\title{
Functional Surface Coating on Cellulosic Flexible Substrates with Improved Water-Resistant and Antimicrobial Properties by Use of ZnO Nanoparticles
}

\author{
Xiaofei Tian, ${ }^{1,2}$ Yaping $\mathrm{Li}^{2,3}$ Sikang Wan, ${ }^{2}$ Zhenqiang Wu, ${ }^{1}$ and Zhiwei Wang ${ }^{2,3,4}$ \\ ${ }^{1}$ School of Bioscience and Bioengineering, South China University of Technology, Guangzhou 510640, China \\ ${ }^{2}$ Guangxi Key Laboratory of Clean Pulp \& Papermaking and Pollution Control, College of Light Industry and Food Engineering, \\ Guangxi University, Nanning 530004, China \\ ${ }^{3}$ State Key Laboratory of Pulp and Paper Engineering, South China University of Technology, Guangzhou 510640, China \\ ${ }^{4}$ Collaborative Innovation Center for Guangxi Sugar Industry, Guangxi, Nanning 530004, China
}

Correspondence should be addressed to Zhiwei Wang; wangzhiwei@gxu.edu.cn

Received 28 October 2016; Accepted 14 December 2016; Published 19 January 2017

Academic Editor: Siya Huang

Copyright (c) 2017 Xiaofei Tian et al. This is an open access article distributed under the Creative Commons Attribution License, which permits unrestricted use, distribution, and reproduction in any medium, provided the original work is properly cited.

It is of significant interest to create functional flexible surfaces that simultaneously exhibit high water-resistance and antimicrobial performances for medical or packaging applications. This study reported a synthesis of functional surface coating on flexible cellulose materials (filter papers) with $\mathrm{ZnO}$ nanoparticles and binds of renewable soybean oil-based polymers. Self-aggregation of $\mathrm{ZnO}$ nanoparticles could form $\mathrm{ZnO}$ particles with two regular morphological patterns. Rather than a rod-like morphology, a flower-like $\mathrm{ZnO}$ benefited a promotion of surface hydrophobicity. Moreover, surface with the flower-like $\mathrm{ZnO}$ showed a $51.6 \%$ promotion on antimicrobial activities against Gram-negative bacteria (E. coli) than the rod-like ZnO. A low binder/ZnO ratio of 0.2 led to a remarkable improvement on water repelling performances without negative effects on a coating adhesion of $\mathrm{ZnO}$. Under this condition, a hydrophobic surface was achieved with a large static contact angle of $138^{\circ}$ when applying $\mathrm{ZnO}$ nanoparticles at a dosage of $3 \mathrm{~g} \mathrm{~m}^{-2}$.

\section{Introduction}

Introduction of flexible cellulose materials such as microfibrillated cellulose or cellulose nanofibers as functional membrane, supporting component or papers in medicinal and electronic and packaging applications, attracts people's great attentions [1-4]. For a nature of existence of -OH group on cellulose surfaces, the ease of absorbing moisture or directly contacting with water during distribution, storage, and application is of great challenge to mechanical endurances or antidegradability of these cellulose materials. Moreover, additional functional properties such as good antibacterial activity were also usually preferred for preparing functional cellulose materials. Surface modification possessed a great promise for a controlled wettability or hydrophobicity of the functional cellulose materials.
The creation or development of hydrophobic surfaces with (or without) antibacterial function on cellulose materials uses a number of technologies, such as, chemical coating methods using a mixture of $1 \mathrm{H}, 1 \mathrm{H}, 2 \mathrm{H}, 2 \mathrm{H}$-perfluorooctyltriethoxysilane, 3-(trimethoxysilyl)-propyldimethyloctadecyl ammonium chloride, and P,P-diphenyl-N-(3-(trimethoxysilyl) propyl) phosphinic amide [5] or fluoroalkyl-functional siloxane [6] through a sol-gel process; laccase-catalyzed hydrophobization with lauryl gallate [7] and grafting with eugenol [8] or ferulic acid [9]; thermochemical fabrication and impregnation of silver nanoparticles with starch [10]; sonochemical cohydrolysis and cocondensation with tetraethyl orthosilicate and alkyltrialkoxysilanes [11]; and physical pad-dry-cure method with $\mathrm{MgO} /$ methyl silicate nanocomposites [12]. 
Other methods such as internal sizing and surface sizing only provide a first barrier for cellulosic substrates against water penetration but often cannot meet the requirements for modern applications [13]. Nowadays, artificial water-resistant surfaces have been fabricated on cellulosic substrate based on selection of appropriate methods to create roughness and/or low surface energy on local surfaces [14]. Fluorinated polymers together with nanoparticles, for example, silica [15] or $\mathrm{ZnO}$ [16], were believed to be effective chemicals in building up water-resistant structure on cellulosic surface [17]. However, if an environment concern was taken into consideration, coating with no-fluorinated materials is preferable technology for preparation of highly hydrophobic surface [18].

$\mathrm{ZnO}$ is an attractive candidate for surface coating application $[19,20]$ due to its considerable antibacterial efficiency [21], stability [22], tunable structure [23], and low toxicity [24]. $\mathrm{ZnO}$ nanoparticles are promising additives for further improving the hydrophobicity through dedicated surface modification [18] such as stearic-acid modification [25, 26]. On the other hand, preventing undesirable microbial spoilage was also an important property for coating materials [19, 27]. $\mathrm{ZnO}$ finds increasing application as an antibacterial material for its promise of withstanding a harsh physical or chemical processing [21], compared to organic antibiotics that were conventionally used [22]. For instance, incorporate $\mathrm{ZnO}$ in hygienic coating for sterile packaging use [28].

Because of the promising functional properties, $\mathrm{ZnO}$ was introduced in this study for creating functional flexible surfaces that simultaneously exhibit high water-resistance and antimicrobial performances that could be subject to medical or packaging applications. $\mathrm{ZnO}$ nanoparticles were applied to build functional layers hierarchically on filter papers as a model of flexible substrate through a surface coating method. Soybean oil-based polymers were used as a green binding reagent for assembling the $\mathrm{ZnO}$ particles with cellulosic fibers. With an optimal coating formulation and application dosages, water repelling properties and antibacterial activities of the composite surface were determined for evaluating its feasibility for medical or packaging applications.

\section{Materials and Methods}

2.1. Materials. Rod-like $\mathrm{ZnO}$ were obtained from Aladdin Biochemical Technology, Co. Ltd. (Shanghai, China). Flowerlike $\mathrm{ZnO}$ were synthesized by a typical hydrothermal method according to the reported method [26]. The average intensitybased hydrodynamic size of $\mathrm{ZnO}$ particles was measured using a Zeta Potential analyzer (ZetaPlus, Instruments Corporation, NY, USA). Cellulose filter paper (Whatman \#2, $106 \mathrm{~g} \mathrm{~m}^{-2}$, GE healthcare Life Sciences, Buckinghamshire, UK) was used as the cellulose substrate. Soybean oil-based polymer for binding $\mathrm{ZnO}$ nanoparticles on the paper surface was prepared according to the procedure reported in our previous study [29]. The chemicals of acrylated epoxidized soybean oil (AESO), 3-aminopropyltriethoxysilane (APTS), benzoyl peroxide (BPO), and anhydrous acetone were mixed with a weight ratio of $1 / 0.3 / 0.004 / 1$. All of the chemicals were purchased from Sigma-Aldrich Corporation (St. Louis, MO, USA).

\subsection{Methods}

2.2.1. Coating $\mathrm{ZnO}$ on Paper Surface. Coating slurry was prepared by mixing $\mathrm{ZnO}$ particles with binder together. In a typical method, $1 \mathrm{~g} \mathrm{ZnO}$ particles (dry mass) was dispersed in $5 \mathrm{~mL}$ ethanol. All the prepared coating slurry was in an equal volume of $5 \mathrm{~mL}$. The binder was gently added into the slurry at the ratio of $0.2-0.6 / 1$ (binder/ $\mathrm{ZnO}, \mathrm{w} / \mathrm{w}$ ).

The paper was coated by a rod coater (K303 Multicoater, RK. Print Coat Instruments Ltd., UK) with the coating slurry at a velocity of $3 \mathrm{~m} \mathrm{~min}^{-1}$. After coating, the paper was immediately transferred for curing at $80^{\circ} \mathrm{C}$ for $30 \mathrm{~min}$ to finalize the bonding of $\mathrm{ZnO}$ particles. Coating weight of the $\mathrm{ZnO}$ varied from $1.5 \mathrm{~g} \mathrm{~m}^{-2}$ to $4.5 \mathrm{~g} \mathrm{~m}^{-2}$.

2.2.2. Characterization of Morphologies and Surface Wettability. The aggregation patterns of the commercial and synthesized $\mathrm{ZnO}$ particles and distributions of $\mathrm{ZnO}$ particles on surface were characterized using a JEOL 6400 scanning electron microscope (JEOL Ltd., Tokyo, Japan). To determine the surface wettability, static contact angles (SCA) of water droplets $(3 \mu \mathrm{L})$ on the surface coating were measured using an optical tensiometer (Attension Theta, Biolin scientific, Stockholm, Sweden) [30]. Measurement was performed for 10 times on each sample.

2.2.3. Antibacterial Assays. Minimum inhibition concentration (MIC) of $\mathrm{ZnO}$ particles against E. coli ATCC 11229 was measured by a dilution method [31]. $\mathrm{ZnO}$ particles with different concentrations were serially diluted in LB broth. The $\mathrm{ZnO}$ dilution and fresh bacterial culture $\left(10^{6} \mathrm{CFU} \mathrm{mL}^{-1}\right)$ were equally mixed by volume and incubated at $37^{\circ} \mathrm{C}$ for $18 \mathrm{~h}$. MIC was determined as the lowest effective concentration of $\mathrm{ZnO}$ in inhibiting a visible growth of bacteria.

The antibacterial activity of the $\mathrm{ZnO}$ surface coating was quantitatively examined through a cultivation method in shaking flasks. A $0.10 \mathrm{~g}$ of paper sample was soaked in a $25 \mathrm{~mL}$ flask containing $5 \mathrm{~mL}$ culture of E. coli $\left(10^{5} \mathrm{CFU} \mathrm{mL}{ }^{-1}\right)$. Shaken at $200 \mathrm{rpm}$, the mixture was incubated at $37^{\circ} \mathrm{C}$ for $60 \mathrm{~min}$. After cultivation, $0.5 \mathrm{~mL}$ culture was successively diluted with $4.5 \mathrm{~mL}$ PBS solution to prepare bacterial dilutions. Finally, $0.1 \mathrm{~mL}$ of the dilution was coated on LB agar plate. After an incubation at $37^{\circ} \mathrm{C}$ for $24 \mathrm{~h}$, the number of bacterial colonies formed was counted. Each paper sample was tested in triplicate. Filter paper without surface coating was used as the paper blank.

A reduction rate of bacterial reproduction was calculated to determine the antibacterial efficiency of the surface coatings by

$$
\text { Reduction rate }(\%)=100 \% \times \frac{(A-B)}{A},
$$

where $A$ and $B$ were the numbers of bacterial colonies formed from the cultures with paper blank and coated papers, respectively. 


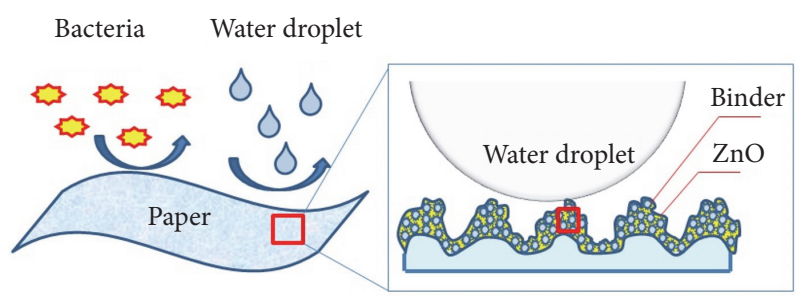

FIGURE 1: Schematic diagram of the surface coating structure.

\section{Results and Discussion}

3.1. Structure of the Surface Coating. The surface wettability of the surface coating was usually determined by two important factors: surface energy and surface roughness [32]. Natural cellulosic surfaces are hydrophilic or highly affiliative to water. In this work, change in hydrophobicity of cellulosic surface was realized due to the hydrophobic properties of soybean oil-based binder [33]. Low surface energy was achieved after incorporating the hydrophobic binder on cellulosic surfaces. At the mean time, the micro- or nanoscale hierarchical structures of $\mathrm{ZnO}$ particles could control the surface roughness (Figure 1).

The use of soybean oil-based polymer in the coating formula as binders relied on its bifunctional roles in the surface coating [34]. On one hand, AESO, the main constituent in the binder, could distribute through chain propagation to form a hydrophobic substance through free-radical reactions. On the other hand, the APTS which attached on AESO through a Michael addition reaction [35] could efficiently provide reactive silanol groups to render covalent bonds between -OH and $\ddot{O}_{2}{ }^{-}$on cellulosic surface and metallic oxide, respectively [33]. The binder was predominantly made up of triglyceride structures and probably possesses a potential degradability [36].

The original pore structure on natrual cellulosic surface and $\mathrm{ZnO}$ particles contributed to the increase of waterresistant property of the coated cellulosic surfaces. The interlaced network of cellulose fibers provided basic microstructure of paper surfaces. $\mathrm{ZnO}$ nanoparticles coating could lead to three-dimensional structural patterns in micro- and nanoscale to form a hierarchical roughness on cellulosic surface. This specific morphology was believed to be more effective in creating air pockets [37] and increasing the water contact angles of the cellulose materials [38].

3.2. Aggregation of Patterns of $\mathrm{ZnO}$ Nanoparticles. In this study, two aggregation patterns of $\mathrm{ZnO}$ nanoparticles, that is, rod-like $\mathrm{ZnO}$ and flower-like $\mathrm{ZnO}$, were introduced and tested separately (Figure 2 ). With an average diameter of $\sim$ $2 \mu \mathrm{m}$, the $3 \mathrm{D}$ structure of the flower-like $\mathrm{ZnO}$ was observed by assembing a large number of $15 \mathrm{~nm}$-thick nano- $\mathrm{ZnO}$ sheets. The nanosheets intersected with each other to form special porous structures on the flower-like $\mathrm{ZnO}$.

Table 1 demonstrates the average diameters of the $\mathrm{ZnO}$ particles with two different aggregation patterns. The hydrodynamic size for both $\mathrm{ZnO}$ particles was relatively lower than that estimated by SEM imaging method.

\subsection{Factors Affecting the Water Repelling Efficiency of Surface Coating}

3.3.1. Patterns of $\mathrm{ZnO}$ Particles. Figure 3 shows that the cellulosic surface is superhydrophilic as the SCA is almost $0^{\circ}$. It could be explained by the existing of free hydroxyl groups that had a strong affinity for water. It demonstrated a strong hydrophobicity of the polymer binder was demonstrated as the hydrophilic cellulosic surface became hydrophobic with a SCA of $106^{\circ}$ when a $0.3 \mathrm{~g} \mathrm{~m}^{-2}$ binding polymer was applied (Figure 3(b)). With introducing of two $\mathrm{ZnO}$ into the coating formula, the SCA of paper was further promoted over $125^{\circ}$ (Figures 3(c) and 3(d)). It could be explained by a formation of hydrophobic substance over the cellulosic substrate followed by a decrease of the surface energy with $\mathrm{ZnO}$ particles. Additionally, the coverage of hydrophobic $\mathrm{ZnO}$ particles introduced micro- and nanoscale roughness, which was able to trap air for forming a solid-air-liquid interface. The multiscale structures, combining micro- and nanometric structuration would provide a remarkable promotion on water-droplet repellency [39]. The use of $\mathrm{ZnO}$ particles and polymer binder realized an improved antiwetting property through a surface morphological modification.

Interestingly, differences of the SCA between $\mathrm{ZnO}$ particles with distinct morphologies were observed. The flowerlike $\mathrm{ZnO}$ was more effective in promoting SCA than the rodlike $\mathrm{ZnO}$. As mentioned above, the flower-like $\mathrm{ZnO}$ particles tended to form a regular three-dimensional pattern full of micro- and nanostructures (Figure 3(d)) that were believed to be more effective in creating air pockets for an increase of SCA [40]. In contrast, the rod-like $\mathrm{ZnO}$ only deposited a flat structure through the surface coating (Figure 3(c)).

3.3.2. Ratio of Polymer Binder and $\mathrm{ZnO}$ in the Formula. The dosages of soybean oil-based binder in the coating agent needs to be adjusted to provide sufficient hydrophobicity as well as to ensure a solid affinity of $\mathrm{ZnO}$ particles on the cellulosic surface. Figure 4 shows that an increase of binder/ZnO ratio always leads to a decrease of SCA on the surface either with the lower-like $\mathrm{ZnO}$ or the rod-like $\mathrm{ZnO}$. Lower ratio benefited a high SCA. The negative effect of an overuse of polymer binder on the SCA could refer to the AESO composition which had caused a loss of surface nanostructures induced by engulfing of $\mathrm{ZnO}$ particles and thus a reduction in roughness in the coating layers [15]. In addition, the reduction of the surface roughness was also attributed to the ease of aggregation of $\mathrm{ZnO}$ particles.

Even with an increased ratio of binder/ $\mathrm{ZnO}$, the flowerlike $\mathrm{ZnO}$ still showed better performances on improving the water repelling efficiency than the rod-like $\mathrm{ZnO}$ did (Figure 4). As all porous structures on the ball-shaped particles could be well filled with the adsorbed binding chemicals, the flower-like $\mathrm{ZnO}$ showed an even distribution pattern on the coating surface. The smaller rod-like $\mathrm{ZnO}$ tended to gather together with the binding chemicals on the cellulosic surface. Considering a firm adhesion of $\mathrm{ZnO}$ particles, a ratio no less than 0.2 should be selected as the optimal level for further application. 


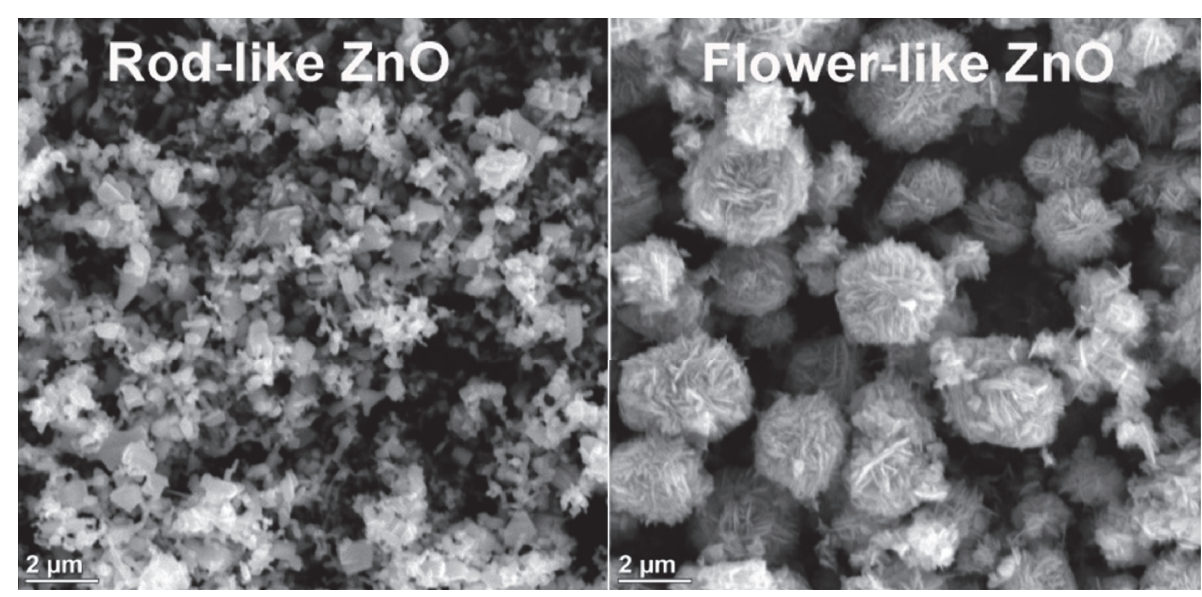

FIgURE 2: SEM images of the nano-ZnO aggregation.

TABLE 1: Particle size and polydispersity of the nano-ZnO aggregation.

\begin{tabular}{lcccc}
\hline Aggregation patterns & \multicolumn{2}{c}{ Hydrodynamic size } & \multicolumn{2}{c}{ SEM observable size } \\
& $\begin{array}{c}\text { Effective } \\
\text { diameter }(\mathrm{nm})\end{array}$ & Polydispersity & \multicolumn{2}{c}{$\begin{array}{c}\text { Average } \\
\text { diameter (nm) }\end{array}$} \\
\hline Rod-like $\mathrm{ZnO}$ & 124.5 & 0.13 & 372.1 & 0.49 \\
Flower-like $\mathrm{ZnO}$ & 521.7 & 0.18 & 2374.1 & 0.30 \\
\hline
\end{tabular}

3.3.3. Coating Weight. An increase application of the coating formula from 1.5 to $3 \mathrm{~g} \mathrm{~m}^{-2}$ promotes the SCA with either of the flower-like $\mathrm{ZnO}$ or the rod-like $\mathrm{ZnO}$ (Figure 5). However, an intensive application of coating weight had a negative effect on the SCA of the cellulosic surfaces. In Figure 6, it is revealed that the coating weight has influenced the surface morphology directly. At a coating weight of $1.5 \mathrm{~g} \mathrm{~m}^{-2}$, the cellulosic surface was only partially coated by the $\mathrm{ZnO}$ particles with binding polymers, leaving the valley area of fiber networks hydrophilic to water. As the increase of the coating weight to $3 \mathrm{~g} \mathrm{~m}^{-2}$, the cellulosic surface was well covered by the hydrophobic coating with a mixture of micro- or nanostructures exposed on the air-water interface. Upon further increasing the coating weight to $4.5 \mathrm{~g} \mathrm{~m}^{-2}$, the cellulosic surface is covered by densely packed layers with a significant loss of micro- or nanohierarchical structures (Figure 6). As the fabrication of micro- or nanostructures on the coating surface would reflect the hydrophobicity performances of materials, choosing proper coating weight as well as a premodification of morphologies of the coating substrate would be possible method to adjusting the SCA on the coating surface.

3.4. Antimicrobial Efficiency of the Surface Coating with $\mathrm{ZnO}$ Nanoparticles. Besides regulating the surface roughness, the $\mathrm{ZnO}$ particles also played a key role in introducing the antimicrobial function to the cellulosic surfaces. Depending on the differences in particle sizes, the bacterial types, and experimental assays, the reported antimicrobial efficiency of $\mathrm{ZnO}$ differed with an effective concentrations ranging from 81 to $2835 \mu \mathrm{g} \mathrm{mL}^{-1}$ [41].
Determination of antibacterial activity of $\mathrm{ZnO}$ particles was performed homogenously as it ensured that $\mathrm{ZnO}$ particles could be well distributed in the bacterial culture [42]. In this study, we also measured a relative inhibating rate for $E$. coli reproduction (reduction rate) alternatively using the filter papers with immobilized-ZnO-polymer coatings. In this study, the flower-like $\mathrm{ZnO}$-polymer coating shows higher antibacterial activity than that of the rod-like $\mathrm{ZnO}$ polymer coating (Table 2 ). The result was consistent with the reported literature [43]. Nevertheless we did not find an obvious difference in the MIC between using flower-like and the rod-like $\mathrm{ZnO}$ (Table 2).

A coating weight of $3 \mathrm{~g} \mathrm{~m}^{-2}$ led to a $51.6 \%$ of reduction rate E. coli reproduction by coating with flower-like $\mathrm{ZnO}$ particles. The reduction rate was comparable to that with the dispersion of free $\mathrm{ZnO}$ particles and the reduced antibacterial efficiencies of the surface coating were mainly from the barrier effects caused by binding polymers [43].

Defect sites could be formed on the flower-like $\mathrm{ZnO}$ with a typical structural pattern of $15 \mathrm{~nm}$-thick nanoplates (Figure 2); that was believed to be responsible for the production of reactive oxygen species (ROS) in antibiosis of E. coli. In addition, an increase of coating weight resulted in an improvement of antibacterial activities for the coating surfaces. Clearly, a higher availability of $\mathrm{ZnO}$ from applying intensive coating weights on cellulosic surfaces corresponded to the promotion on release of ROS [44].

\section{Conclusion}

Functional flexible cellulosic surfaces with water-resistant and antimicrobial properties were prepared through a coating 


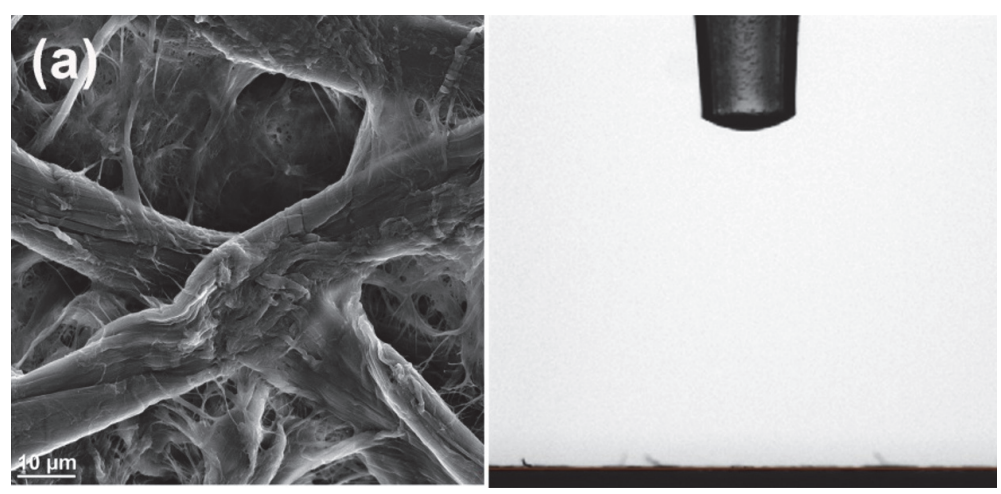

(a)

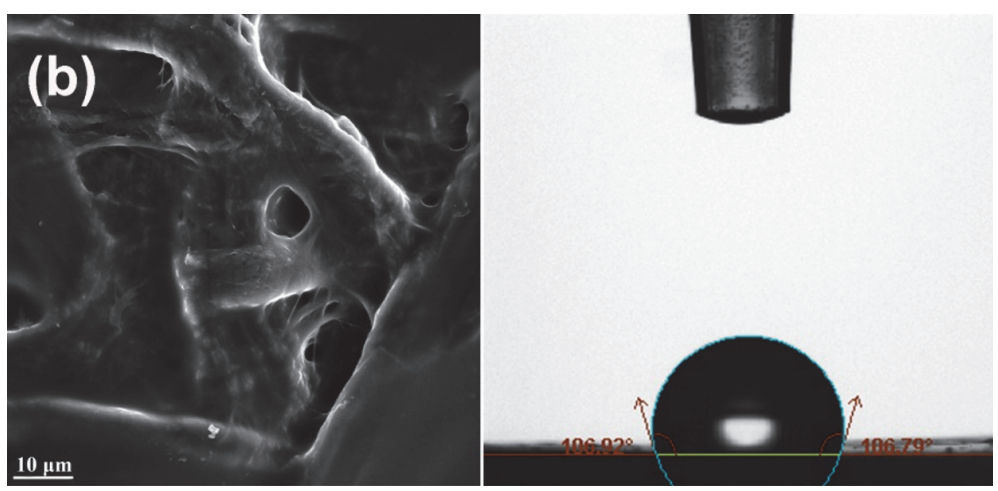

(b)

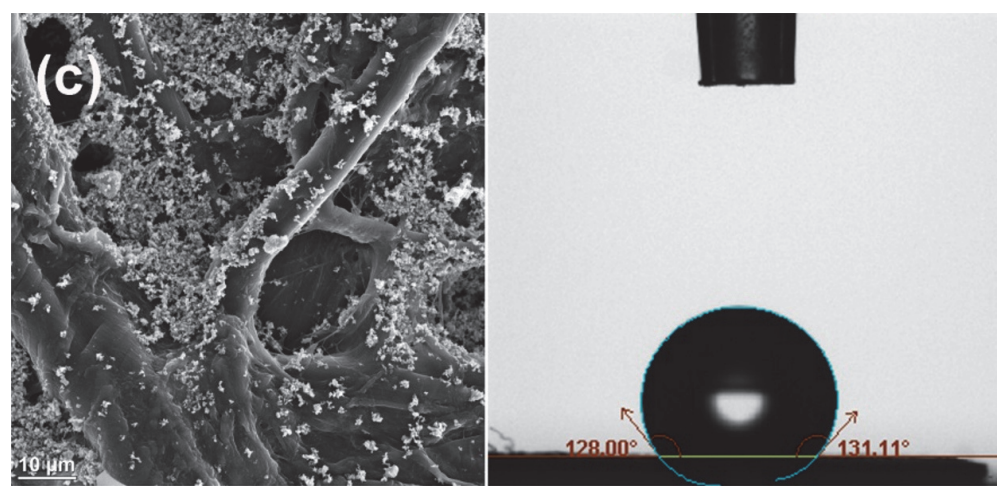

(c)

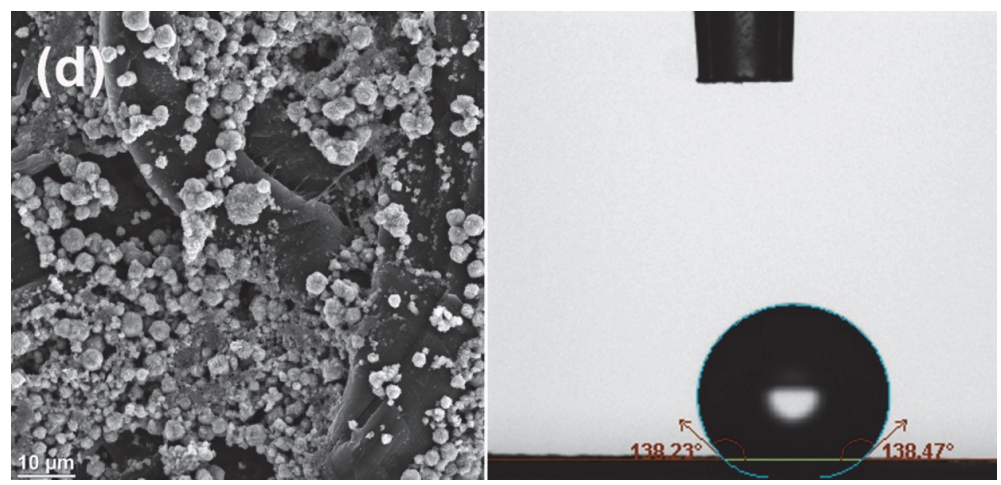

(d)

FIGURE 3: SEM images and SCA of (a) cellulosic surface; (b) cellulosic surface + binder; (c) cellulosic surface + binder + rod-like ZnO; and (d) cellulosic surface + binder + flower-like $\mathrm{ZnO}$ (with binder $/ \mathrm{ZnO}$ ratio $=0.2$ ). 


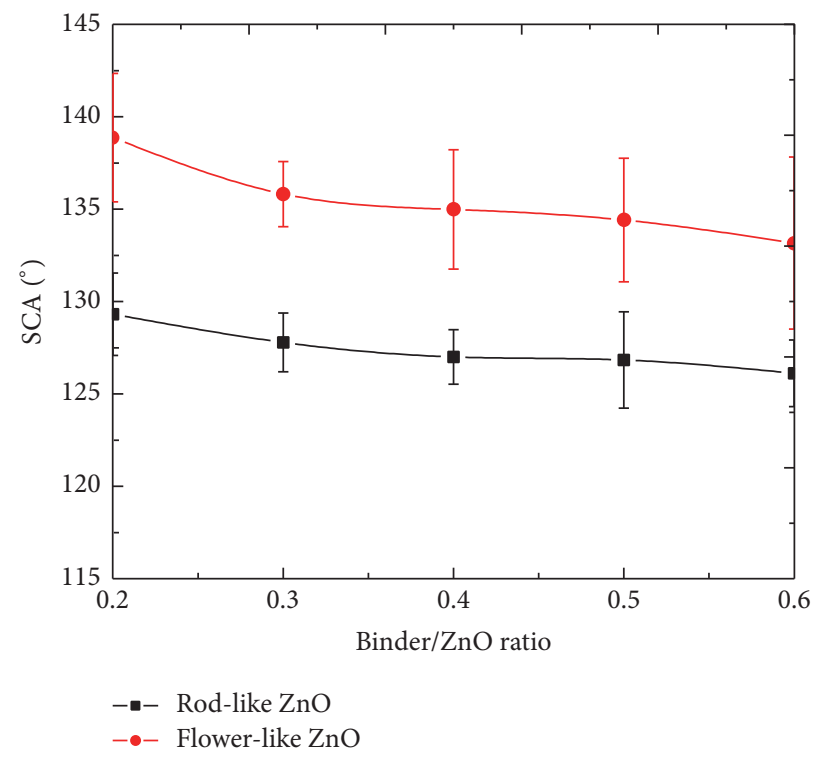

FIGURE 4: Effect of the binder/ZnO ratio on the SCA of coating surfaces.

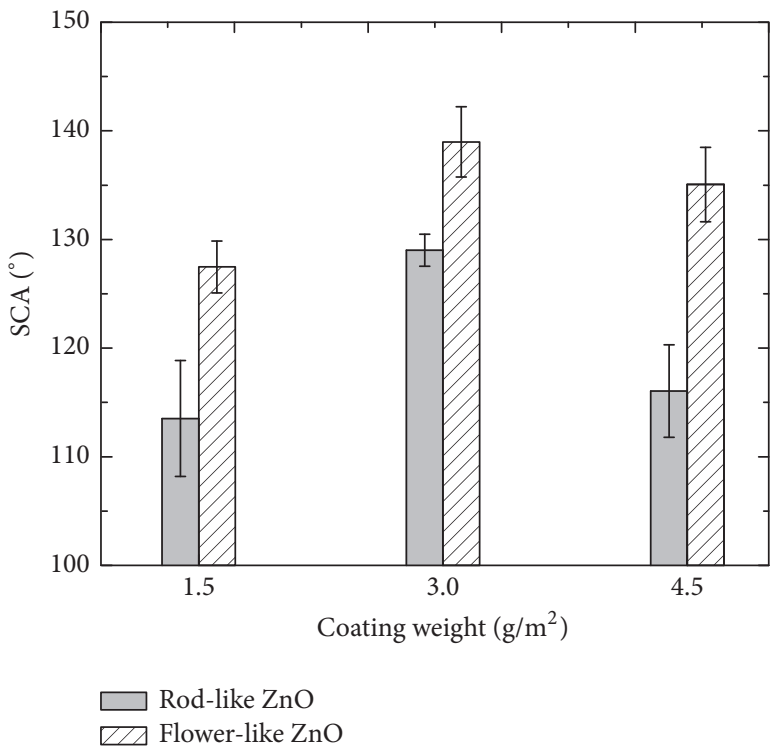

FIGURE 5: Effect of coating weight on the SCA of coating surfaces (with binder/ZnO ratio = 0.2).

TABLE 2: Antimicrobial performances of the surface coating with different $\mathrm{ZnO}$ aggregations.

\begin{tabular}{|c|c|c|c|}
\hline & \multirow{2}{*}{$\begin{array}{c}\text { MIC } \\
\left(\mu \mathrm{g} \mathrm{mL}^{-1}\right)\end{array}$} & \multicolumn{2}{|c|}{ Reduction of E. coli reproduction (\%) } \\
\hline & & ${ }^{*}$ Coating weight of $1.5 \mathrm{~g} \mathrm{~m}^{-2}$ & ${ }^{*}$ Coating weight of $3 \mathrm{~g} \mathrm{~m}^{-2}$ \\
\hline Control & 0 & 0 & 0 \\
\hline Rod-like $\mathrm{ZnO}$ & 312.5 & 34.0 & 45.3 \\
\hline Flower-like $\mathrm{ZnO}$ & 312.5 & 44.9 & 51.6 \\
\hline
\end{tabular}

${ }^{*}$ Binder $/ \mathrm{ZnO}$ ratio $=0.2$. 


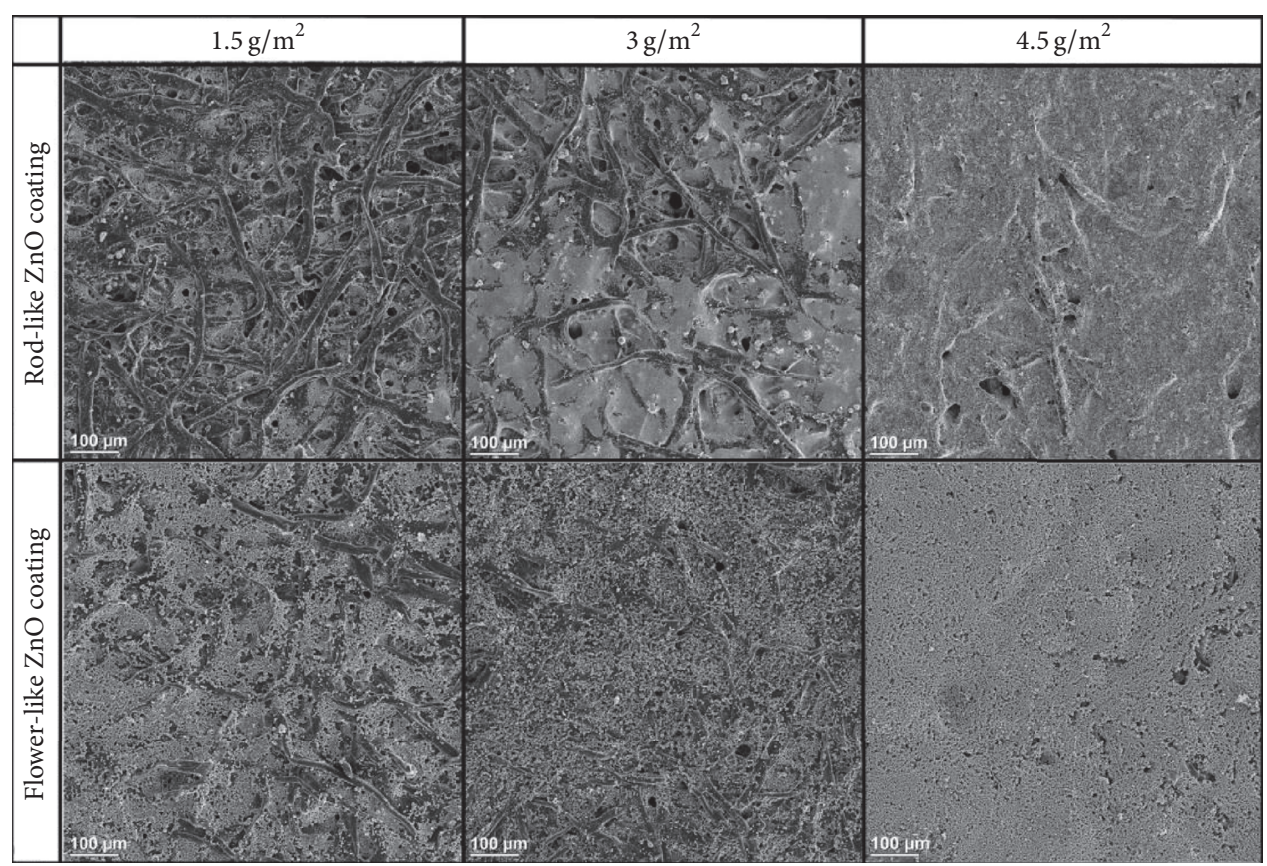

FIGURE 6: SEM images of the coating surface at different coating weight (with binder/ZnO ratio $=0.2$ ).

method with $\mathrm{ZnO}$ nanoparticles and soybean oil-based polymers. The flower-like structural pattern of $\mathrm{ZnO}$ effectively promoted the SCA and antimicrobial activities. Under the optimal conditions with a binder/ZnO ratio of 0.2 and coating weight of $3 \mathrm{~g} \mathrm{~m}^{-2}$, the prepared functional surfaces showed improved hydrophobic and antibacterial advantages with a SCA value of $138^{\circ}$ and a $51.6 \%$ reduction rate for inhibiting E. coli reproduction.

\section{Competing Interests}

The authors declare that there is no conflict of interests regarding the publication of this paper.

\section{Acknowledgments}

The authors acknowledge the financial support from Scientific Research Foundation of Guangxi University (Grant no. XGZ160294), the Research Fund of State Key Laboratory of Pulp and Paper Engineering (no. 201351), and the National Science Foundation of Guangxi (no. 2015GXNSFBA139042). This research was also supported by the Opening Project of Guangxi Key Laboratory of Clean Pulp \& Papermaking and Pollution Control, Nanning 530004, China (KF201603).

\section{References}

[1] S. Liu, T. Yu, Y. Wu, W. Li, and B. Li, "Evolution of cellulose into flexible conductive green electronics: a smart strategy to fabricate sustainable electrodes for supercapacitors," RSC Advances, vol. 4, no. 64, pp. 34134-34143, 2014.

[2] Y. H. Jung, T.-H. Chang, H. Zhang et al., "High-performance green flexible electronics based on biodegradable cellulose nanofibril paper," Nature Communications, vol. 6, article 7170, 2015.

[3] H. G. de Oliveira Barud, R. R. da Silva, H. da Silva Barud et al., "A multipurpose natural and renewable polymer in medical applications: bacterial cellulose," Carbohydrate Polymers, vol. 153, pp. 406-420, 2016.

[4] H. P. S. Abdul Khalil, Y. Davoudpour, C. K. Saurabh et al., "A review on nanocellulosic fibres as new material for sustainable packaging: process and applications," Renewable and Sustainable Energy Reviews, vol. 64, pp. 823-836, 2016.

[5] J. Vasiljević, B. Tomšič, I. Jerman, B. Orel, G. Jakša, and B. Simončič, "Novel multifunctional water- and oil-repellent, antibacterial, and flame-retardant cellulose fibres created by the sol-gel process," Cellulose, vol. 21, no. 4, pp. 2611-2623, 2014.

[6] J. Vasiljević, M. Gorjanc, B. Tomšič et al., "The surface modification of cellulose fibres to create super-hydrophobic, oleophobic and self-cleaning properties," Cellulose, vol. 20, no. 1, pp. 277289, 2013.

[7] J. Garcia-Ubasart, J. F. Colom, C. Vila, N. G. Hernández, M. Blanca Roncero, and T. Vidal, "A new procedure for the hydrophobization of cellulose fibre using laccase and a hydrophobic phenolic compound," Bioresource Technology, vol. 112 , pp. 341-344, 2012.

[8] K. Thakur, S. Kalia, B. S. Kaith et al., "The development of antibacterial and hydrophobic functionalities in natural fibers for fiber-reinforced composite materials," Journal of Environmental Chemical Engineering, vol. 4, no. 2, pp. 1743-1752, 2016.

[9] K. Thakur, S. Kalia, D. Pathania, A. Kumar, N. Sharma, and C. L. Schauer, "Surface functionalization of lignin constituent of coconut fibers via laccase-catalyzed biografting for development of antibacterial and hydrophobic properties," Journal of Cleaner Production, vol. 113, pp. 176-182, 2016.

[10] Z. A. Raza, A. Rehman, M. Mohsin et al., "Development of antibacterial cellulosic fabric via clean impregnation of silver 
nanoparticles," Journal of Cleaner Production, vol. 101, pp. 377386, 2015.

[11] M. Shateri-Khalilabad and M. E. Yazdanshenas, "One-pot sonochemical synthesis of superhydrophobic organic-inorganic hybrid coatings on cotton cellulose," Cellulose, vol. 20, no. 6, pp. 3039-3051, 2013.

[12] N. R. Dhineshbabu, P. Manivasakan, A. Karthik, and V. Rajendran, "Hydrophobicity, flame retardancy and antibacterial properties of cotton fabrics functionalised with $\mathrm{MgO} /$ methyl silicate nanocomposites," RSC Advances, vol. 4, no. 61, pp. 3216132173, 2014.

[13] P. Samyn, "Wetting and hydrophobic modification of cellulose surfaces for paper applications," Journal of Materials Science, vol. 48, no. 19, pp. 6455-6498, 2013.

[14] H.-B. Jo, J. Choi, K.-J. Byeon, H.-J. Choi, and H. Lee, "Superhydrophobic and superoleophobic surfaces using $\mathrm{ZnO}$ nano-inmicro hierarchical structures," Microelectronic Engineering, vol. 116, pp. 51-57, 2014.

[15] H. Ogihara, J. Xie, J. Okagaki, and T. Saji, "Simple method for preparing superhydrophobic paper: spray-deposited hydrophobic silica nanoparticle coatings exhibit high water-repellency and transparency," Langmuir, vol. 28, no. 10, pp. 4605-4608, 2012.

[16] D. Ebert and B. Bhushan, "Transparent, superhydrophobic, and wear-resistant coatings on glass and polymer substrates using $\mathrm{SiO}_{2}, \mathrm{ZnO}$, and ITO nanoparticles," Langmuir, vol. 28, no. 31, pp. 11391-11399, 2012.

[17] G. Gonçalves, P. A. A. P. Marques, T. Trindade, C. P. Neto, and A. Gandini, "Superhydrophobic cellulose nanocomposites," Journal of Colloid and Interface Science, vol. 324, no. 1-2, pp. 4246, 2008.

[18] J. Li, Z. Jing, F. Zha, Y. Yang, Q. Wang, and Z. Lei, "Facile spraycoating process for the fabrication of tunable adhesive superhydrophobic surfaces with heterogeneous chemical compositions used for selective transportation of microdroplets with different volumes," ACS Applied Materials and Interfaces, vol. 6, no. 11, pp. 8868-8877, 2014.

[19] V. Chaurasia, N. Chand, and S. K. Bajpai, "Water sorption properties and antimicrobial action of zinc oxide nanoparticlesloaded cellulose acetate films," Journal of Macromolecular Science Part A: Pure and Applied Chemistry, vol. 47, no. 4, pp. 309317, 2010 .

[20] F. Fu, L. Li, L. Liu et al., "Construction of cellulose based $\mathrm{ZnO}$ nanocomposite films with antibacterial properties through onestep coagulation," ACS Applied Materials \& Interfaces, vol. 7, no. 4, pp. 2597-2606, 2015.

[21] N. C. T. Martins, C. S. R. Freire, C. P. Neto et al., "Antibacterial paper based on composite coatings of nanofibrillated cellulose and ZnO," Colloids and Surfaces A: Physicochemical and Engineering Aspects, vol. 417, pp. 111-119, 2013.

[22] G. Applerot, J. Lellouche, N. Perkas, Y. Nitzan, A. Gedanken, and E. Banin, "ZnO nanoparticle-coated surfaces inhibit bacterial biofilm formation and increase antibiotic susceptibility," RSC Advances, vol. 2, no. 6, pp. 2314-2321, 2012.

[23] K. Han, Z. H. Zhao, Z. Xiang, C. Wang, J. Zhang, and B. Yang, "The sol-gel preparation of $\mathrm{ZnO} /$ silica core-shell composites and hollow silica structure," Materials Letters, vol. 61, no. 2, pp. 363-368, 2007.

[24] P. Joshi, S. Chakraborti, P. Chakrabarti et al., "Role of surface adsorbed anionic species in antibacterial activity of $\mathrm{ZnO}$ quantum dots against Escherichia coli, Journal of Nanoscience and Nanotechnology, vol. 9, no. 11, pp. 6427-6433, 2009.
[25] A. B. Gurav, S. S. Latthe, R. S. Vhatkar et al., "Superhydrophobic surface decorated with vertical $\mathrm{ZnO}$ nanorods modified by stearic acid," Ceramics International, vol. 40, no. 5, pp. 71517160, 2014.

[26] Y. Wang, B. Li, and C. Xu, "Fabrication of superhydrophobic surface of hierarchical $\mathrm{ZnO}$ thin films by using stearic acid," Superlattices and Microstructures, vol. 51, no. 1, pp. 128-134, 2012.

[27] T. K. Sontakke, R. N. Jagtap, A. Singh, and D. C. Kothari, "Nano $\mathrm{ZnO}$ grafted on MAA/BA/MMA copolymer: an additive for hygienic coating," Progress in Organic Coatings, vol. 74, no. 3, pp. 582-588, 2012.

[28] T. J. Athauda, R. R. Ozer, and J. M. Chalker, "Investigation of cotton functionalized with $\mathrm{ZnO}$ nanorods and its interaction with E. coli," RSC Advances, vol. 3, no. 27, pp. 10662-10665, 2013.

[29] P. Lu, X. Tian, Y. Liu, and Z. Wang, "Effects of cellulosic base sheet pore structure and soybean oil-based polymer layer on cellulosic packaging performance as a barrier for water and water vapor," BioResources, vol. 11, no. 4, pp. 8483-8495, 2016.

[30] M. Yu, Z. Wang, H. Liu et al., "Laundering durability of photocatalyzed self-cleaning cotton fabric with $\mathrm{TiO}_{2}$ nanoparticles covalently immobilized," ACS Applied Materials \& Interfaces, vol. 5, no. 9, pp. 3697-3703, 2013.

[31] M. He, H. Xiao, Y. Zhou, and P. Lu, "Synthesis, characterization and antimicrobial activities of water-soluble amphiphilic copolymers containing ciprofloxacin and quaternary ammonium salts," Journal of Materials Chemistry B, vol. 3, no. 18, pp. 3704-3713, 2015.

[32] M. Ma and R. M. Hill, "Superhydrophobic surfaces," Current Opinion in Colloid \& Interface Science, vol. 11, no. 4, pp. 193-202, 2006.

[33] M. Marquez, B. P. Grady, and I. Robb, "Different methods for surface modification of hydrophilic particulates with polymers," Colloids \& Surfaces A: Physicochemical \& Engineering Aspects, vol. 266, no. 1-3, pp. 18-31, 2005.

[34] P. Lu, H. Xiao, W. Zhang, and G. Gong, "Reactive coating of soybean oil-based polymer on nanofibrillated cellulose film for water vapor barrier packaging," Carbohydrate Polymers, vol. 111, pp. 524-529, 2014.

[35] S. Çolak and S. H. Küsefoğlu, "Synthesis and interfacial properties of aminosilane derivative of acrylated epoxidized soybean oil," Journal of Applied Polymer Science, vol. 104, no. 4, pp. 22442253, 2007.

[36] H.-M. Kim, H.-R. Kim, and B. S. Kim, "Soybean oil-based photo-crosslinked polymer networks," Journal of Polymers and the Environment, vol. 18, no. 3, pp. 291-297, 2010.

[37] E. Bormashenko, "Progress in understanding wetting transitions on rough surfaces," Advances in Colloid and Interface Science, vol. 222, pp. 92-103, 2015.

[38] T. P. N. Nguyen, R. Boukherroub, V. Thomy, and Y. Coffinier, "Micro-and nanostructured silicon-based superomniphobic surfaces," Journal of Colloid and Interface Science, vol. 416, pp. 280-288, 2014.

[39] N. J. Shirtcliffe, G. McHale, S. Atherton, and M. I. Newton, "An introduction to superhydrophobicity," Advances in Colloid and Interface Science, vol. 161, no. 1-2, pp. 124-138, 2010.

[40] D. E. Weibel, A. F. Michels, A. F. Feil, L. Amaral, S. R. Teixeira, and F. Horowitz, "Adjustable hydrophobicity of Al substrates by chemical surface functionalization of nano/microstructures," The Journal of Physical Chemistry C, vol. 114, no. 31, pp. 1321913225, 2010. 
[41] V. B. Schwartz, F. Thétiot, S. Ritz et al., "Antibacterial surface coatings from zinc oxide nanoparticles embedded in poly $(\mathrm{N}-$ isopropylacrylamide) hydrogel surface layers," Advanced Functional Materials, vol. 22, no. 11, pp. 2376-2386, 2012.

[42] M. Li, L. Zhu, and D. Lin, "Toxicity of $\mathrm{ZnO}$ nanoparticles to Escherichia coli: mechanism and the influence of medium components," Environmental Science \& Technology, vol. 45, no. 5, pp. 1977-1983, 2011.

[43] J. T. Seil and T. J. Webster, "Antimicrobial applications of nanotechnology: methods and literature," International Journal of Nanomedicine, vol. 7, no. 1, pp. 2767-2781, 2012.

[44] M. Ramani, S. Ponnusamy, and C. Muthamizhchelvan, "From zinc oxide nanoparticles to microflowers: a study of growth kinetics and biocidal activity," Materials Science and Engineering C, vol. 32, no. 8, pp. 2381-2389, 2012. 

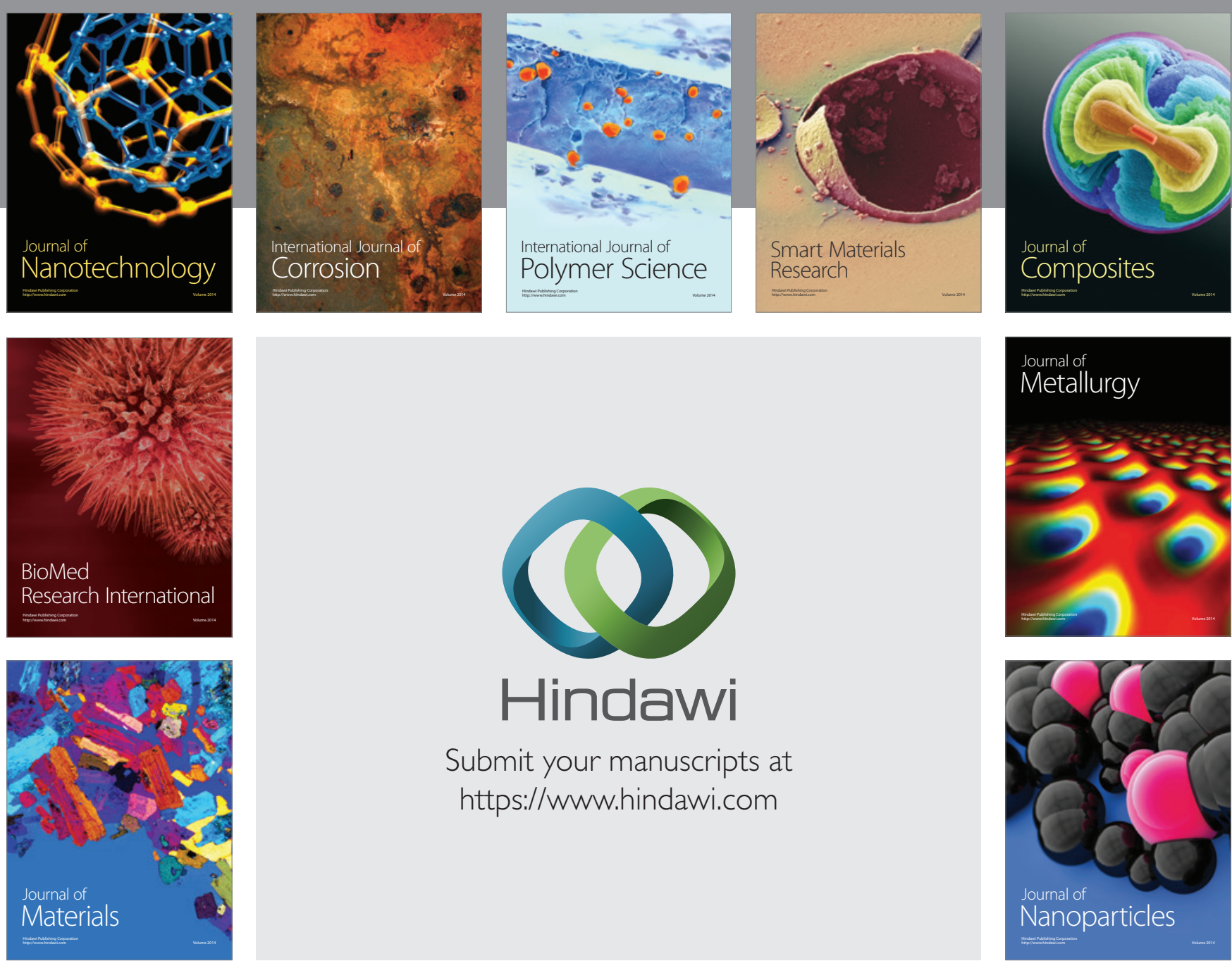

\section{Hindawi}

Submit your manuscripts at

https://www.hindawi.com

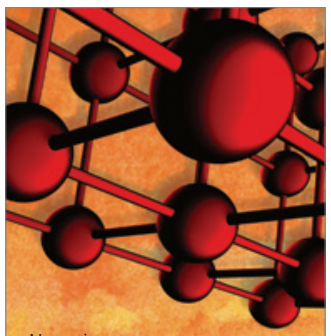

Materials Science and Engineering
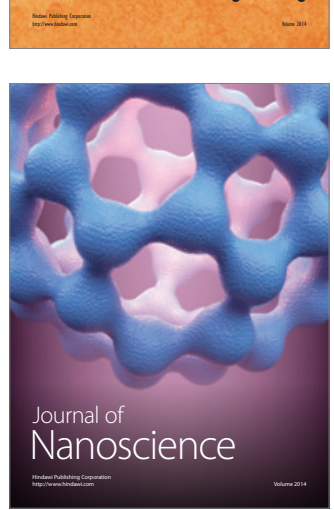
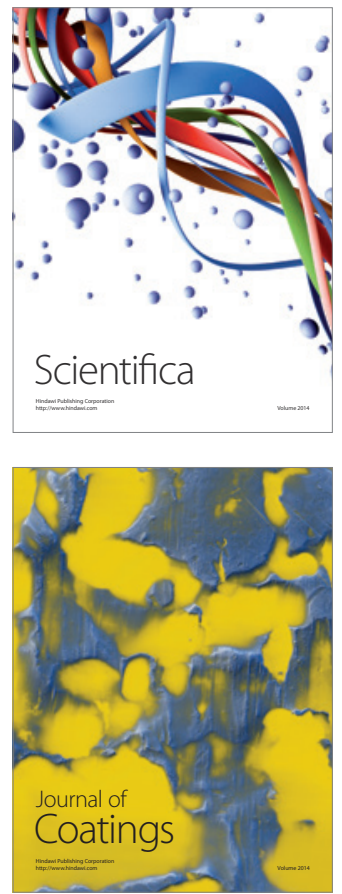
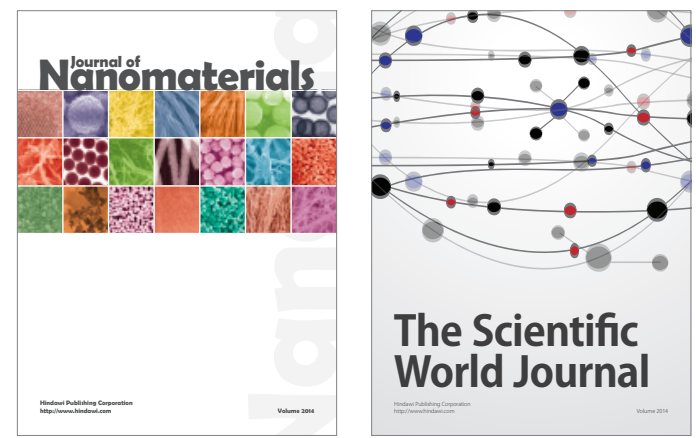

The Scientific World Journal
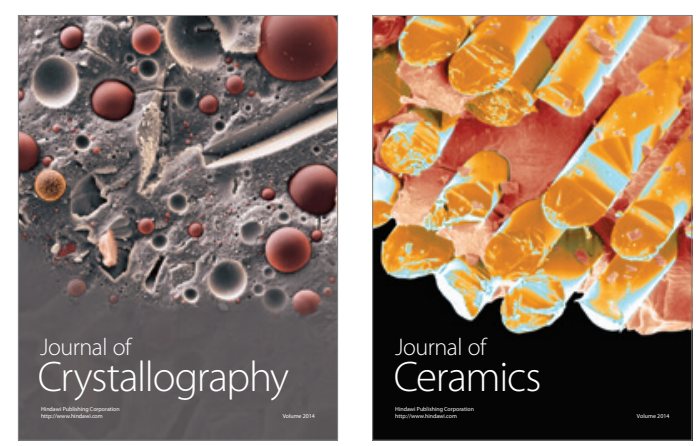
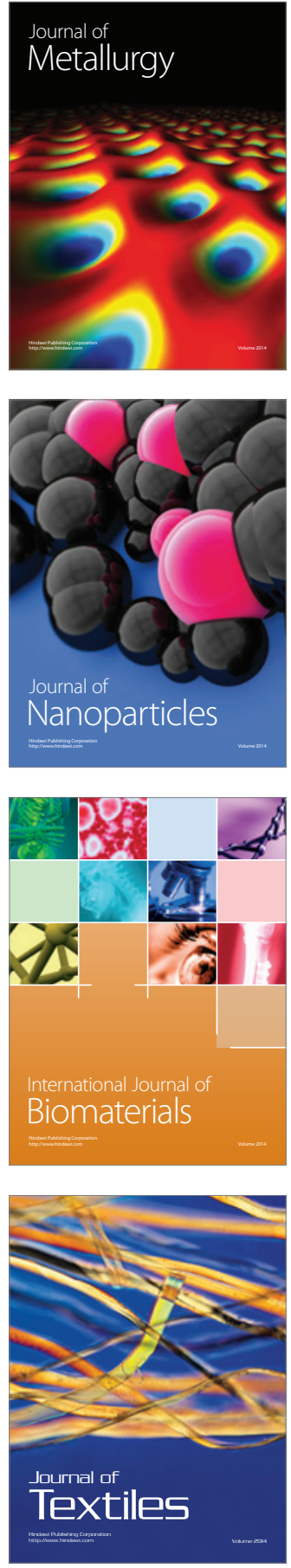